\title{
Parametric Assay of Energy Adept Clustering Protocols for Het-Net Wireless Sensor Networks
}

\author{
Ridhi Kapoor, Sandeep Sharma
}

\begin{abstract}
With the receptiveness in Micro-Electro-Mechanical-System (MEMS), workgroup computing, as well as wireless information computing have facilitated heterogeneous wireless sensor networks (Het-Net) as rapidly growing technological era. Thus, to incorporate such applications the WSNs must be energy adept so as to have increased Network Lifespan, Shrunk Network Costs Using Clustering, Compressive Sensing, and Data Fusion (Aggregation) \& Efficient Routing Protocols over Spatially Disseminated Sensing Nodes. The sensor nodes have confined sensing, processing, and communication potentialities, due to constrained battery life, and in most of the scenarios, it is almost unfeasible to outplace the sensors during complete energy dissipation. Therefore, energy preservation is the major need of WSN existence. In this paper we have done the extensive analysis of the numerous parameters like network lifetime, number of Super Nodes (cluster heads) at each iteration, number of viable nodes per iteration, throughput, inter-cluster topology, type of heterogeneity, level of heterogeneity, etc. which in turn are directly proportional to Network Operational cost.
\end{abstract}

Keywords: Clustering, Data Fusion, Het-Net Wireless Sensor Network; Lifetime, Sensing Motes, Stability Region, Steady and Unsteady Clustering.

\section{INTRODUCTION}

A Heterogeneous WSN (or Het-Net) subsists of a numerous minute, low-power Sensing Motes organized with variable abilities like sensing range, computing power, bandwidth, energy, memory, and radio access technologies (RAT), etc. which are either deployed haphazardly or manually over designated target areas[1]. The motes are the sensing nodes responsible for successively monitoring the designated areas and sending the processed packets towards the Sink Node bearing the highest computational energy. The Base Station plays the role of a pylon between motes and the system server that stores and forwards the processed data to the network server either using one hop or multiple hops transmission $\operatorname{link}[17]$

Revised Manuscript Received on October 30, 2019.

* Correspondence Author

Ms. Ridhi Kapoor*, Department of Computer Engineering and Technology, Guru Nanak Dev University, Amritsar, India. Email: ridhikapoor89@gmail.com

Dr. Sandeep Sharma, Department of Computer Engineering and Technology, Guru Nanak Dev University, Amritsar, India. Email: sandeep.cse@gndu.ac.in

(C) The Authors. Published by Blue Eyes Intelligence Engineering and Sciences Publication (BEIESP). This is an open access article under the CC-BY-NC-ND license http://creativecommons.org/licenses/by-nc-nd/4.0/
Therefore numerous amount of energy is wasted in data transmission rather than on data storage and processing. As with the expansion in network size, the performance of flat (non-clustered) network decreases due to more and more energy dissipation in transmitting and receiving by distinctive nodes of the network, hence Clustering in HWSNs is one of the effective methods to eliminate this shortcoming[17][7]. There are numerous amount of hierarchical heterogeneous wireless sensor network protocols that will help in balancing energy consumption, increase in the effectiveness of computation and storage of network and increase network reliability by deploying the nodes with variable capabilities[6]. In a heterogeneous network, nodes are categorized into supernodes and sensor nodes due to their different energy capacities. Supernodes are the special nodes with the highest energy amongst other nodes of a cluster and are culled out as Cluster Heads so as to fuse the data of multiple sensors and address to their respective base stations since the maximum amount of energy is used in dispatching and gathering. Clustering with the heterogeneous deployment of network nodes helps in refraining the problem of the creation of 'Energy Holes' in the network thereby enhancing network operational time. In comparison to homogeneous deployment where each node was deployed with the same sensing abilities, heterogeneous network prevails in context to shrunken hardware cost, optimal resource utilization and prolonged network lifetime because of varying capabilities of nodes like relay nodes, clusters heads, etc. which contribute to help nodes with minimum energy to easily communicate with base station by aggregating their data elements. Further, some nodes with maximum available or residual energy in a heterogeneous environment can achieve compressive sensing of data to achieve load balancing in the network[9]. A sensor network is made ascendable by Clustering, where clustering is an unsupervised learning technique in which the arrangement of network sensors with variable energy efficacies is based on distance or proximity (adjacency) of sensing nodes relative to each other. Each cluster is under the supervision of a particular Cluster Head. On the basis of maximum residual energy, minimum reachability to the base station and the count of adjacent neighbors the Cluster Head is elected, which has a frequent significance in prolonging the lifetime of a network and is also subjected for Data Fusion (Aggregation), Load Balancing, reduced rate of network's energy consumption. 


\section{Parametric Assay of Energy Adept Clustering Protocols for Het-Net Wireless Sensor Networks}

\section{Clustering ALgorithMS FOR HETEROGENEOUS NETWORKS:}

A. SEP (A Stable Election Protocol for clustered Heterogeneous Wireless Sensor Networks)- Georgios S et al.[23] had projected Stable Election protocol to lengthen the lifetime of the network on the basis of its Stability Region or Period. The SEP nodes are classified as Normal and Advanced nodes footing on their respective levels of the initial energy, where the sensing motes with lower levels of the energy are termed as normal nodes (assigned with weighted election probability of $P_{n m m}$ ) and the sensing motes with higher energy value are termed as Advanced nodes(assigned with weighted election probability of $P_{\text {adv }}$ )

$$
\begin{gathered}
\boldsymbol{P}_{\text {nrm }}=\frac{\boldsymbol{P}_{\text {opt }}}{1+\alpha \cdot m} \boldsymbol{\&} \boldsymbol{P}_{\text {adv }}=\frac{\boldsymbol{P}_{\text {opt }}}{1+\alpha \cdot m} *(1+\boldsymbol{\alpha}) \\
\boldsymbol{P}_{\text {opt }}=\frac{\text { initinl energy of each ndoe }}{\text { initinl energy of normal node }}
\end{gathered}
$$

$m$ indicates the portion of advanced nodes and $\alpha$ refers to the added energy factor between advanced and the normal nodes. The total energy of the HetNet with $n$ (initial sensor populace), $E_{0}$ represents the initial energy of normal sensing mote and $E_{0} \cdot(1+\alpha)$ represents the initial energy of advanced sensing mote is equal to:

$\left(n \cdot(1-m) \cdot E_{0}+n \cdot m \cdot E_{0} \cdot(1+\alpha)\right)=n \cdot E_{0} \cdot(1+\alpha \cdot m)$ (3)

Hence the system's total energy is increased by $(1+a, m)$ times in SEP and assumes that energy across the network is utilized in an equitable manner thereby prolonging the Stable Region of the network.

\section{B. H-HEED(Heterogeneous-HybridEnergy-Efficient}

Distributed Protocol)- Harneet Kour et al[13] proposed this protocol which systematically nominates and choose cluster heads footing on the hybridization of prime factor of remaining energy of the node and trivial factors as node's proximity to adjoining sensors or degree of the node to reduce inter-cluster communication cost. It terminates in constant time following $\mathrm{O}(1)$ iterations, and helps in the creation of well-distributed clusters and ensures that every sensor is a member of an exclusive cluster. It is presumed that the sensing nodes of the network are quasi-stationary, also the links between nodes are symmetric. The entire set of sensing nodes have proportionate processing and communication competence but varying energy rates. After deployment nodes are left untended due to therefore recharging of batteries is not possible. The main drawback to this is location unawareness of deployed nodes due to absentia of GPS systems.

C. CHR (Cluster Head Relay Routing Protocol)- Du and Lin[25] proposed a passive and location-aware heterogeneous routing methodology. It relies on the deployment of dual types of sensing nodes to form an operational HetNet using a single operable sink node.

- L-Sensor nodes: Low-End sensors nodes with lesser energy value are deployed in large numbers. They can be used only for limited-range data communication to the respective adjoining nodes.

- H-Sensor nodes: High-end powerful sensor nodes with more energy value and deployed in small numbers. They can be used for long-distance communication to their respective neighboring $\mathrm{H}$-sensing nodes as well as to the sink.
Both kinds of sensing nodes are immobile and are knowledgeable about their predefined locales with the usage of certain location marking service. Furthermore, both of the L-sensor and $\mathrm{H}$-sensors have been consistently and haphazardly deployed in the sensor field. This protocol segregates the entire network into uniform clusters, where each cluster comprises L-sensors which are directed by an $\mathrm{H}$-sensor. Inreach of a cluster, the L-sensors are supervisory of perceiving the environmental factors, so as to forward the sensed parametric values created by subordinating L-sensor nodes, towards their corresponding cluster heads in a multi-hop routing fashion. On the contrary, the H-sensors are intended to perform data aggregation inside their owned clusters along with forwarding fused packets of the data originated from different cluster heads towards adjoining $\mathrm{H}$-sensing nodes and the base station.

D. DEEC (Deterministic Energy Efficient Clustering Protocol)- Qing et al[21] proposed a dual phased algorithm for the election of the cluster head where the function of Cluster head is rotated amongst advanced nodes to dispense consistent energy across the network. In the initial stage, indefinite cluster heads are elected by the contingency of nodes dependent on initial and residual energy. During the secondary phase, the newer cluster head replaces the existing Cluster head if any of the cluster member's enduring energy is greater than the existing cluster head. This algorithm considers two-level heterogeneity of nodes and further extends it to multi-level heterogeneity. The energy consumption is well dispersed across the network. This works well only in the situation where the sink node is stationed at the midway of the sensing field and its sensing capabilities reduce if the base station is quite distant from the sensing motes. The optimal value of network lifetime is evaluated by this algorithm to gauge out the energy count that every sensor should expend amidst every iterative round ${ }^{(r)}$. Furthermore, a presumption is made that, the m.N advanced nodes are outfitted by an initial energy factor $E_{0}(1+\alpha)$ and $(1-m) . N$ normal nodes are outfitted by an initial energy factor $E_{0}$. Where two of the variables ${ }^{\alpha}$ and ${ }^{m}$ are required to administer the nodes percentage types i.e. advanced or normal. Based on such presumptions, the totality of the network's initial energy is calculated as:

$$
E_{\text {total }}=\left(N \cdot(1-m) \cdot E_{0}+N \cdot m \cdot E_{0} \cdot(1+\alpha)\right)
$$

Each node's average energy count in the $r^{\text {th }}$ round is computed as:

$$
E_{\text {avg }}=\frac{1}{N} E_{\text {total }}\left(1-\frac{r}{R}\right)
$$

Where $\mathrm{R}$ designates the estimated count of all the rounds throughout the lifetime of a network and is computed as:

$$
\boldsymbol{R}=\frac{E_{\text {total }}}{E_{\text {round }}}
$$

Where $E_{\text {round }}$, represents the amount of energy spent in a sensing field in a particular round and is estimated as:

$$
E_{\text {round }}=L\left(2 N E_{\text {elec }}+\mathrm{N} E_{d a}+\mathrm{k} E_{m p} d_{\text {toBs }}^{4}+N E_{f s} d_{\text {toCH }}^{2}\right.
$$


Where $\mathrm{k}$ designates the total count of clusters, $\boldsymbol{E}_{\text {da }}$ is the data fusion energy $\boldsymbol{d}_{\text {toBs }}$ represents the approximate expanse of the sink node from the cluster head and $\boldsymbol{d}_{\text {toc }}$ represents the approximate expanse of the cluster head from the respective cluster members. Presumptuous to the uniform node distribution, $d_{\text {toCH }}=\sqrt[M]{\sqrt{2 k \pi}}, d_{\text {toBs }}=0.75^{M} / 2$, the $L_{\text {-bits of }}$ the message are transmitted over distance $d$ (between transmitter and receiver), $E_{\text {elec }}(n j / b i t)$ signifies the amount of energy squandered per bit to operate the radio circuitry, $E_{f s}$ energy squandered in free space, $E_{m p}$ signifies the energy squandered in multipath fading channel where $d^{2}$ (power dissipation in free space) and $d^{4}$ (power dissipation in multipath fading channel).

E. UCR (An unequal cluster-based routing protocol)Guihai chen. et al.[10] proffered a protocol for allaying the hot spot issue in HWSNs. It is devised to operate source directed application of the sensor networks, as the studying of environment and detecting its cyclical data. It is a self-formulated competitive methodology, wherein the cluster head selection is based on the enduring energy values of the neighboring sensing nodes. In this protocol, the sensing nodes are organized into unevenly sized clusters. With the increase in the communication range amongst the base station and cluster head, the extent of their corresponding clusters also increases. The consistent dissipation of energy across the network is affected by varying sizes of clusters and by facilitating the higher relaying load capacity nearer to the base station. This protocol works on two main axioms as:

- The time complexity of the system in the composition of the cluster is $O(n)$ thereby signifying reduced data overhead of the system.

- Two accompanying nodes cannot be cluster head at the same instant if one of them is in another competing sphere.

\section{F. DEBC(Distributed Energy Balance Clustering} Protocol for Heterogeneous Wireless Sensor Networks)Changmin D et al.[3] projected a methodology in which the choice of the cluster head is positioned at the proportion of the node's residual energy to the network's average energy. The sensing motes with the highest values of initial and residual energy have the highest likelihood of being Cluster head repeatedly. It is based on 2-level or multi-level heterogeneity. DEBC chooses a node ${ }^{i}$ to be a cluster head in $n_{\mathrm{i}}$ iterations as per the node's residual energy $E_{i}^{k}$ in the round ${ }^{k}$ and $p_{\mathrm{i}}$ represents node ${ }^{i}{ }^{\prime} s$ probability to come up as a cluster head in $n_{\mathrm{i}}$ iterations. The nodes with the largest values of initial and residual energies have the highest likelihood of being Cluster head repeatedly. The network's average energy in the $\mathrm{k}^{\text {th }}$ round is calculated as- $\left(\overline{E^{k}}=\sum_{i=1}^{N} E_{i}^{k}\right)$, where $\mathrm{N}$ symbolizes the total count of sensing nodes. Knowing the value of $\overline{E^{k}}$ it is compared with the sensor's residual energy based on the required proportion of cluster heads ${ }^{(p)}$ and $p_{\mathrm{i}}$ is estimated as:

$$
p_{i}=p\left[1-\frac{E^{\mathbb{k}}-E_{i}^{k}}{\overline{E^{k}}}\right]=p \frac{E_{E^{k}}^{k}}{E^{k}}
$$

According to the above equation if the node's residual energy is higher as compared to the network's average energy, then the sensing-node has the highest chance of being a cluster head.

\section{G. PRODUCE (Probability Driven Unequal Clustering} Mechanism for WSNs)- Jung-Hwan Kim et.al[12] proposed a haphazardly loosely coupled clustering algorithm using multi-hop routing, which consists of unevenly dispersed clusters. The cluster head nearer to the sink node is more convergent towards inter-cluster (amongst members of the same cluster) communication, while the distant ones will be convergent towards intra-cluster (amongst different clusters) communication. It balances the network subjective to the hot-spot problem of the network. The algorithm works on the following ideology:

Division: During network deployment, the Base station or Sink node which is presumed to be stationary and positioned at network's inmost broadcasts the "hello" packets to the respective network nodes. Using the received signal strength each node computes its proximity from the base station to know how distant it is from the base station. Sensor node's proximity to the sink node concerning the average one-hop distance is computed which is called as level, where the level is calculated as:

$$
\text { Level }_{i}=d\left(S_{k}, B S\right) / h_{1}
$$

where $d\left(S_{k}, B S\right)$ designates the distance between $k^{\text {th }}$ the sensing node and the sink node, Level $_{i}$ denotes on which level $k^{\text {th }}$ sensor is deployed and ${ }^{h_{1}}$ represents the one-hop distance of each node.

Calculation of maximum communication distance and their respective probabilities: After a threshold distance $\left(d_{\text {cross }}\right)$ between transmitter and receiver, the propagation attenuation starts increasing. So it is always kept into consideration to keep the distance $\leq\left(d_{\text {cross }}\right)$, by using multi-hop communication for a longer sphere so as to curtail the attenuation of the signal. The parameters $P_{\text {cross }}$ and Level $_{i}$ are used to regulate with what probability non- $\mathrm{CH}$ nodes become CH (advanced nodes). Every level is associated with a varying probability factor, thence, the designated probabilities fluctuate between $P_{\text {cross }}$ and $P_{\max }$ where $P_{\max }$ is the probability accredited to the sensing nodes at level 1 , while $P_{\text {cross }}$ represents the probability for nodes at the $\mathrm{n}^{\text {th }}$ level(i.e. last level) and is the least value of probability allotted to nodes level. This implies that $\mathrm{CH}$ nearer to the base station has more responsibility for data fusion and relaying of data from upper-level $\mathrm{CHs}$ in order to have equitable energy utilization across the network. For each sensing mote, the probability assigned is calculated as:

$$
\boldsymbol{P}_{\text {CH }}=\boldsymbol{P}_{\text {cross }}+{ }^{\left(\boldsymbol{P}_{\max }-\boldsymbol{P}_{\text {cross }}\right) / n-1} \mathbf{1}^{* n-i}
$$

where ${ }^{P_{C H}}$ represents the possibility of being a Cluster Head, ${ }^{i}$ represents the level of clustering hierarchy, $n$ represents last level number and $P_{\max }$ the highest probability value of the first level and $P_{\text {cross }}$ the lowest probability value of $n^{\text {th }}$ level. The equation depicts that with the decrease in Cluster Level the probability of being Cluster Head increases. 


\section{Parametric Assay of Energy Adept Clustering Protocols for Het-Net Wireless Sensor Networks}

H. C4SD (Cluster Based Service Discovery for Heterogeneous WSN)- Marin et al.[18] proposed an energy-adept utility discovery protocol for HetNets to work in an easily accessible and continuously changing network scenarios. It relies on the conception of implementing a self-organizing robust clustering methodology that constitutes a distributed directory of service enrollments, in which decision formulation relies on single-hop neighborhood information where clustering criterion acts spontaneously to the regional anatomical changes in the configuration. The criterion od the co-optation of the cluster heads usually comprises of:

- The parametric distribution of every sensing mote either across the complete network or to the cluster of sensors.

- The contrasting of parametric values in order to select the relevant nodes as Cluster Heads.

The chosen cluster head nodes enact to be directories to ensure utility supply to their respective cluster members i.e. Intra-Cluster Services. This structural configuration assures reduced overhead in network deployment and sustenance and responds at a quicker pace to the topological diversifications to refrain the chain-reaction problems. During the initial stage of cluster formation, such topology need not be static in nature. In order to assure low disclosure cost, only Cluster Heads are visited in context to service lookup of the network.

I. EEHC (Energy Efficient Heterogeneous Clustered Scheme for Wireless Sensor Networks)- D. Kumar et al.[15] projected this model which is intended for optimal computation of cluster heads over uniformly distributed nodes in a field. This algorithm modifies the LEACH protocol of a homogeneous network and justifies how network lifetime is prolonged by increased energy factor. The algorithm segregates the nodes as supernodes, advanced nodes, and normal sensor nodes, where super nodes own the larger proportion of energy in comparison to the normal sensors. Let $\mathrm{p}$ signifies the portion of the complete count of nodes $n$, as well as $p_{0}$ signifies the part of the complete count of sensing nodes $p$ outfitted with $\beta$ times extraneous energy factor compared to the normal sensing nodes, such nodes are termed as Super Nodes. The remaining $\left(n *\left(1-p_{0}\right)\right)_{\text {sensors possess }}$ increased energy by a factor of ' $\alpha$ ' by the normal nodes thus are referred to as Advanced Nodes and remaining $(n *(1-p))$ comes under the Normal Sensing Unit. Let $E_{0}$ be the normal sensing node's initial energy, $E_{0}(1+\beta)$ be the energy factor possessed by the super sensing nodes and the energy factor possessed by that of advanced sensing nodes be $E_{0}(1+\alpha)$, then the total value of the initial energy factor so as to set up a heterogeneous network is:

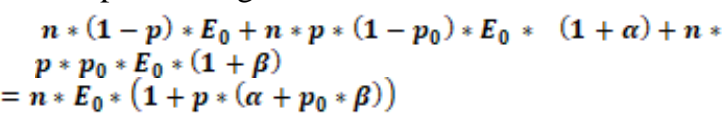

Hence the system's total energy acceleration factor is $\left(1+p *\left(\alpha+p_{0} * \beta\right)\right.$ as compared to homogeneous LEACH systems.

J. SDEEC (Stochastic Distributed Energy Efficient Clustering)- B. Elbhiri et al.[5] proposed a modified DEEC strategy for HetNets(Heterogeneous wireless sensor networks). The protocol works over splitting the entire network into dynamic clusters, where every node communicates with advanced node i.e. Cluster Head for inter and intracluster data fusion (aggregation) and communicating that to the Sink Node i.e. Base Station. It works on a stochastic scheme for the network lifetime prolongation. Once the clustering segment is done, the $\mathrm{CH}$ devises the TDMA slots for the sensing units in which they are allowed to disseminate the data. Only the non- $\mathrm{CH}$ nodes having a sensed value larger than the sensed value of $\mathrm{CH}$ should keep their receivers on i.e. can send data either to cluster head $\left(d_{b s}>d_{c h}\right)$ or to respective base-station $\left(d_{b s} \leq d_{c h}\right)$. The clustering technique works on the concept of data transmission by non-CH sensing nodes to their respective $\mathrm{CHs}$ in their designated frame of time. The $\mathrm{CH}$ is required to retain its receiving antenna in "on" mode so as to accept every data element from its respective cluster members and then the received signals are condensed into simple compressed data signal, so that it can be transmitted in an energy-efficient manner to the intermediate cluster head or directly to the base station based on distance proximity. In context to energy conservation, all the cluster members can shut off their antennas and change their state from awake to sleeping once they have sent all their data to the respective $\mathrm{CH}$. The considerable shortcoming of this strategy is if the nodes will keep their antennas off then how will the get to identify about the afterward cluster head election iteration and won't revive to be a competitor for the same.

K. CMHT (Cluster Multi-Hop Transmission for Heterogeneous Wireless Sensor Networks)- Xuegong et al.[20] had introduced a novel clustering technique to improve the heterogeneous networks(HWSNs) survival time using FND (First node dead) and HNA (Half of the Nodes Alive) parameters. This protocol segregates the entire network into two categories:

a. The one which cannot directly reach and connect to the base station.

b. The other ones can instantly connect to the sink node.

The node selection process involves selecting a node $n$ which will send information containing certain weight value $Q(i)$ which is sensed by all other nodes in the network, which then compares the sensed weight value with their own value. It is presumed that, if the weight value of the sensor is larger as compared to the weight $Q(i)$ then sensing node cannot be elected as a $\mathrm{CH}$ and will compete in the upcoming iterations as well and if its value is $<Q(i)$ the node can be a $\mathrm{CH}$ taking into account it possesses the least weight value in comparison to other nodes.

$Q(i)=q_{1} * E_{c}(i) * \frac{E_{0}(i)-E_{c}(i)}{\frac{\sum_{1}^{n} E_{c}(i)}{n}}+q_{2} * T(i)+q_{3} *$ dist

$q_{1}, q_{2}, q_{3}$ as the positive weight values, $E_{c}(i)$ be the node's current energy, $E_{0}(i)$ be the node's initial energy, $T(i)$ signifies the times of being a cluster head and dist represent the sensor's proximity to the network's sink. The data transmission amongst cluster heads occurs in a Multi-hop fashion. CMHT protocol offers certain advantages as:

- An improved method of cluster head election using weighting factors so that each node can get a fair share of being a cluster head using dynamic adjustment of parameters like the rate of energy absorption, node's average and remaining energy absorption rate, etc. 
- Balanced energy consumption, by reducing the excessive consumption of node energy which was the major cause of increased node dead rate thereby reducing the Cluster Chain Block phenomenon in which failure of one cluster head can block the functioning of other cluster nodes.

- With the improved and extended resistant phase of data communication i.e. Stability Region, the number of re-establishment of clusters is reduced and also the frequency of formation of cluster heads is also reduced to prolong the network survival time.

- Using Multi-Hop transmission methodology it can be used for long-distance communication in an energy-efficient manner.

\section{DDEEC (Developed Distributed Energy-Efficient} Clustering)- Elbhiri et al.[4] proffered modified version DEEC as DDEEC, where DDEEC implements the same methodology for calculating the network's average energy as well as to select the cluster head like that in DEEC. DDEEC differs from DEEC in the sense that, in DEEC every time the advanced nodes are targeted to become the cluster head, hence their rate of energy depletion and node dead probability increases. Nonetheless, it is probable at an instant that a certain count of the advanced nodes will persist to exhibit the same amount of the residual energy as exhibited by normal sensors. Since DEEC persists to target only the advanced nodes, such a situation is not the optimal way, as exclusively such sensors will frequently be a cluster head, thus will die at a quicker pace than that of the normal sensors. However, in DDEEC amongst all the sensors the ones with more residual energy (may or may not be an advanced node) at $r^{\text {th }}$ round has a greater chance of being elected as a cluster head.

M. TDEEC (Threshold Distributed Energy Efficient Clustering protocol)- Saini and K. Sharma[19] proffered an energy-adept cluster head election strategy for HWSN(Heterogeneous Wireless Sensor Network) based on the following premises that Heterogeneity lies in context to the energy value of nodes i.e. nodes with a higher value of the energy are referred to as advanced nodes and those with lesser energy value are categorized as normal nodes.

In TDEEC, the threshold value is dependent on the proportion of residual energy and average energy of respective iteration with respect to the optimal count of the cluster heads. Such that the sensors bearing maximum residual energy factor can only become the $\mathrm{CH}$. The relevant threshold value is computed as:

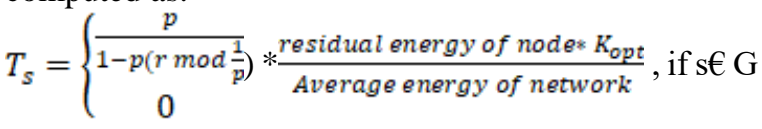

Where p, r, and $\mathrm{G}$ depict, the desiderate possibility for sensing nodes being $\mathrm{CHs}$, count off current clustering round, and the collection of the sensors which have never acted as $\mathrm{CHs}$ in the concluding $1 / p$ rounds. Utilizing the value of the threshold, every sensor can compete to be cluster head, exclusively at a certain period within $1 / \mathrm{p}$ rounds.

N. WEP: An Energy-Efficient Weighted Election Protocol Protocol for Cluster-Based Heterogeneous Wireless Sensor Network- Md. Golam Rashed et.al.[8] proffered an energy-adept cluster-based routing methodology as to embellish the stability region of a network. It associates the clustering approaches accompanying the chain routing algorithm to placate the energy and stable region restraint in heterogeneous networks. This protocol focuses on lengthening the time before the first node dies i.e. Improved Stability Region, using a constraint of well-stabilized energy utilization. The following assumptions have been made in this protocol:

a. Every node is enough energy efficient to transfuse the sensed data either directly towards the base station or directed towards the intermediate nodes.

b. The energy level heterogeneity segregates the nodes of the networks into advanced and normal nodes where advanced nodes vary from normal nodes by an extraneous ' $\alpha$ ' element of energy

c. Owing to more energy value, advanced nodes have a higher probability of being cluster heads, but not a restriction always.

d. The nodes are immobile.

In WEP weights are assigned to the optimum probability $p_{\text {opt }}$ of each sensing unit, which is equivalent to every sensing unit's initial energy divided by the normal sensing unit's initial energy. Once weighted probabilities are assigned to every node, the cluster head, and its respective cluster members are elected following the same methodology as followed in the LEACH. Subsequently, the greedy approach of chain routing is used to make a chain of cluster heads (random election of chain leader) to relay the packets of the data towards the sink node.

O. EAERP: Energy-aware evolutionary routing protocol for dynamic clustering of wireless sensor networks- EnanA.Khalil et.al[11] in context to main challenges in WSNs i.e. optimizing energy consumption and prolonging network lifetime suggested that evolutionary computing can be used as a meta-heuristics for the optimization of a pertinent energy-adept objective function. A unified single-hop clustering technique is proposed in which the base station optimizes the cluster head election by operating the evolutionary protocol during the process of clustering. Considering a WSN having $\mathrm{N}$ sensory units, the population individual incorporates $\mathrm{N}$ genes, whose genetic factor can either be 0 for Non-CH sensing units or 1 for $\mathrm{CH}$ sensing units and -1 signifies dead-nodes (inactive or sedentary sensing units). So the population, $I^{n}$ of $n$ solutions be stated as:

$$
\begin{aligned}
& \forall_{i} \in\{1,2, \ldots, n\} \text { and } \forall_{j} \in\{1,2, \ldots, N\} \\
& I_{j}^{\tilde{u}}=\left\{\begin{array}{c}
1 \text { if } E\left(\text { node }_{j}\right)>0 \text { and node } e_{j}=C H \\
0 i f E\left(\text { node }_{j}\right)>0 \text { and node } e_{j}=\text { non }-C H \\
-1 \quad \text { otherwise }
\end{array}\right.
\end{aligned}
$$

The fitness value of every population individual is calculated using fitness function as:

$\varphi_{E A E R P}\left(I^{k}\right)=\left(\sum_{i=1}^{n e} \sum_{S E E_{i}} E_{T X_{R, E H_{i}}}+E_{R X}+E_{D A}\right)+\sum_{i=1}^{n e} E_{T X_{C E W_{i} B S}}$;

Where; nc is the total count of clusters, $\sec _{\mathfrak{i}}$ represents a non-CH node correlated with the ${ }^{i^{\text {th }}} \mathrm{CH}$ node, ${ }^{E_{T X_{n}, E W_{i}}}$ is the energy exhausted to transfer the data packets from the non-CH node up to its $\mathrm{CH}$ and ${ }^{E_{T X_{C H} B \overline{B S}}}$ signifies the energy exhausted to transmit the packets of data through the $\mathrm{CH}$ node to Sink. 
On the premises of the fitness values, its parents are elected for the creation of a newer population with the help of mutation and crossover operations. This mechanism is reciprocated to the cessation value of the evolutionary algorithm that takes place. At the course of the association stage, the fittest solution amongst the population is kept into consideration as a Clustering Solution.

\section{P. EACP: ENERGY AWARE CLUSTERING} PROTOCOL- Surender Kumar et.al[16] proposed the energy-adept 3-tier clustering protocol for 2-level HetNet sensors communication where heterogeneity can be classified as normal and advance nodes. Herein EACP the cluster heads amongst normal nodes are tabbed by modifying their threshold equation grounded on the basis of the residual and average energy of the normal sensing nodes, ensuring that the normal sensing unit with the greater amount of energy residues can as be competent in becoming cluster head. On contrary, the advanced nodes use a distinct probability-driven methodology for the election of the $\mathrm{CH}$ which in turn acts as a gateway to the normal-CHs and addresses their respective compressed data to the sink node, while they are not carrying out the function of being cluster head. For the sake of the energy conservation across the network, the sensors can switch over to the sleeping mode during cluster formation i.e. when no transmission is taking place.

Q. BEENISH: Balanced Energy Efficient Network Integrated Super Heterogeneous Protocol for WSNQureshi et. al.[22] projected a novel BEENISH protocol as an advancement to the DEEC protocol in WSN that is solely reliant on the sensing node's residual energy and network's average energy as for the election of Cluster Head nodes. It segregates the node composition across the network into four major domains as Normal Sensors, Advance Sensors, Super Sensors, and Ultra-Super Sensors. The Ultra-Super sensing units are culled out to be cluster heads in correlation to Super, Advanced and Normal Sensors. It is termed as a Single-Hop reactive routing protocol which always castigates the high energy nodes; which in turn depletes their energy at a faster pace.

R. IDHR and MEEC: Improved Dual Hop Routing protocol and Multiple data Sink-Based Energy Efficient Cluster-Based Routing Protocol- Sandeep Verma et.al[24] proposed energy-efficient clustering-oriented routing protocols wherein election of cluster head is reliant on the parameters like node density assimilated with the sensing node's residual energy, the approximate distance amongst the sensing units and the base station. IDHR uses a single sink node and MEEC comprises multiple sink nodes in order to achieve dual-hop and single-hop communication across the network respectively.

IDHR: It works on the concept of node density in which node selection as a cluster head is fomented by electing the one which owes the largest number of nodes in its proximity. It focuses on Inter-cluster communication up-gradation by computing the average distance of a normal sensing unit to its respective base station which will help the base station determining the single-hop or multi-hop data transmission.

MEEC: It is hereby proposed to alleviate the hot-spot problem with the deployment of the multi-data sinks. Doing so will not only increase network reliability but will also improve the stability region of the network. The realization of Load balancing is of foremost importance in MEEC. Multiple data sinks deployment compacts the burden on Relay Nodes in Data Forwarding. 
Table1: Parametric analysis of various Heterogeneous WSN Clustering approaches: from Inception to Recent Era

\begin{tabular}{|c|c|c|c|c|c|c|c|c|c|c|c|c|c|c|}
\hline \multirow{2}{*}{ 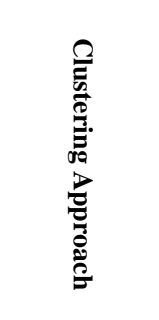 } & \multirow{2}{*}{ 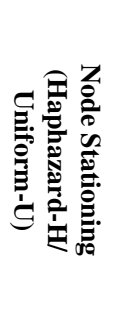 } & \multirow{2}{*}{ 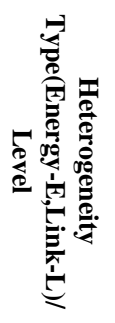 } & \multirow{2}{*}{ 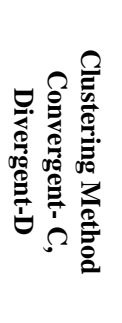 } & \multirow{2}{*}{ 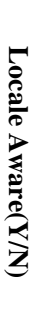 } & \multirow{2}{*}{ 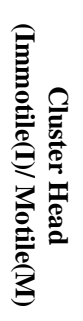 } & \multicolumn{6}{|c|}{ 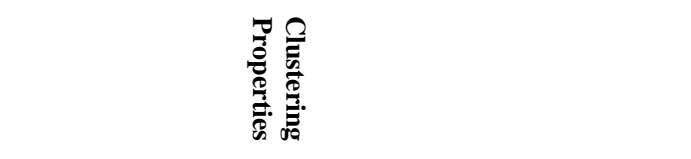 } & \multicolumn{3}{|c|}{ 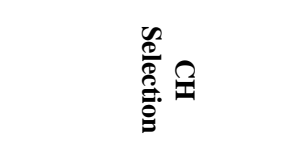 } \\
\hline & & & & & & 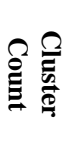 & 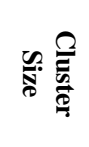 & 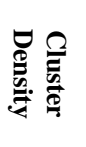 & 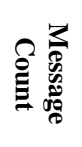 & 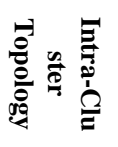 & 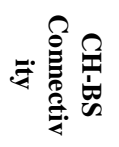 & 哥 & 四罢 & 赵 \\
\hline SEP & \pm & $\frac{\mathbb{T}}{N}$ & $\theta$ & $\mathbf{N}$ & $\mathbf{I}$ & ○ & ○鸹 & ○。 & $\mathbf{N}$ & 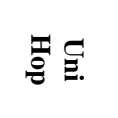 & ț & 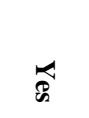 & 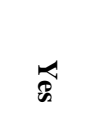 & ' \\
\hline CHR & $I$ & $\frac{\mathrm{T}}{\mathrm{N}}$ & $\theta$ & $\mathbf{Y}$ & I & $\frac{\frac{n}{2}}{\frac{D}{n}}$ & ○ & 。㤩 & $\mathbf{N}$ & 妾总弯 & 总总总 & 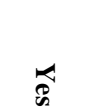 & ' & ' \\
\hline DEEC & $I$ & 当 & $\theta$ & $\mathbf{N}$ & I & ○ & ○ & ○。 & $\mathbf{N}$ & 훰 & 胥 & ' & 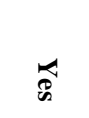 & 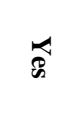 \\
\hline DEBC & $I$ & 尝葸 & $\theta$ & $\mathbf{N}$ & $\mathbf{I}$ & ○ & ○ & ค & $\mathbf{N}$ & 홍 & gृ & ' & 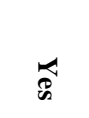 & 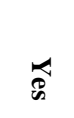 \\
\hline PRODUCE & $I$ & - 賞 & $\theta$ & $\mathbf{Y}$ & $\mathbf{I}$ & ○ & ○ & ○。 & $\mathbf{Y}$ & gृ & gृ & s & 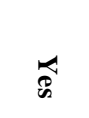 & $\stackrel{乛}{\infty}$ \\
\hline C4SD & $I$ & $-\cdot \frac{5}{3}$ & 0 & $\mathbf{Y}$ & M & ๑ & ○ & ค & $\mathbf{N}$ & 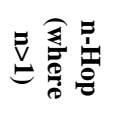 & 点总总 & 承 & ' & ' \\
\hline EEHC & $I$ & ○ & $\theta$ & $\mathbf{N}$ & I & ○ & ○焉 & ○志 & $\mathrm{N}$ & 홍 & $\begin{array}{l}\text { 뮤. } \\
\stackrel{0}{2}\end{array}$ & ' & 8 & ' \\
\hline СMHT & $I$ & $\frac{\mathrm{T}}{\mathrm{N}}$ & $\theta$ & $\mathbf{N}$ & $\mathrm{s}$ & ๑ & ○ & ○。 & $\mathbf{N}$ & 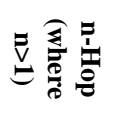 & 蛋管 & ' & 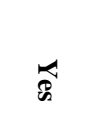 & 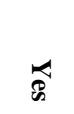 \\
\hline DDEEC & $I$ & $\frac{\mathbb{T}}{\mathrm{N}}$ & $\theta$ & $\mathbf{N}$ & $\mathrm{s}$ & ○ & ○ & ○。 & $\mathbf{N}$ & 马̊ & 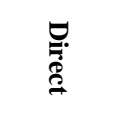 & क & 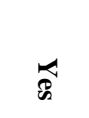 & ' \\
\hline TDEEC & $I$ & $\frac{\mathrm{T}}{\mathrm{N}}$ & $\theta$ & $\mathbf{N}$ & $\mathrm{s}$ & ○ & ○ & ○。 & $\mathbf{N}$ & 홍 & 봄 & ' & 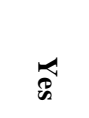 & ' \\
\hline WEP & $I$ & $\frac{\pi}{N}$ & $\theta$ & $\mathbf{N}$ & $\mathrm{s}$ & $\frac{n}{\frac{n}{\sigma}}$ & ○颜 & ○。 & $\mathbf{Y}$ & 홍 & 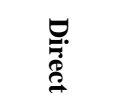 & 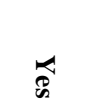 & ' & ' \\
\hline EAERP & $I$ & 个㽣 & $\theta$ & $\mathbf{Y}$ & $\mathrm{s}$ & ○ & ○志 & ○。 & $\mathbf{N}$ & 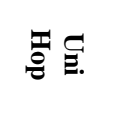 & 莣 & ' & 8 & ' \\
\hline BEENISH & $I$ & $\stackrel{T}{A}$ & $\theta$ & $\mathbf{N}$ & $\mathrm{s}$ & ○ & ○ & ○ & $\mathbf{N}$ & 害 & 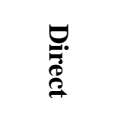 & ' & 8 & 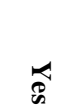 \\
\hline IDHR & $I$ & $\frac{\pi}{\omega}$ & $\theta$ & $\mathbf{N}$ & $\mathrm{s}$ & ○ & ○鸹 & ○。 & $\mathbf{N}$ & 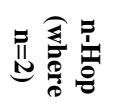 & 寄苞 & क & $\$$ & 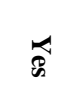 \\
\hline MEEC & \pm & $\frac{\pi}{\omega}$ & $\theta$ & $\mathbf{N}$ & $\mathrm{s}$ & ○ & ○ & ○。 & $\mathbf{N}$ & ğ & 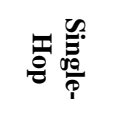 & 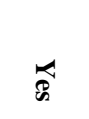 & 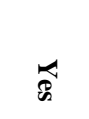 & $\$$ \\
\hline
\end{tabular}


Parametric Assay of Energy Adept Clustering Protocols for Het-Net Wireless Sensor Networks

Table2: Comparison of Heterogeneous WSN protocols based on QoS parameters

\begin{tabular}{|c|c|c|c|c|c|c|c|}
\hline Protocol & $\begin{array}{c}\text { Routing } \\
\text { Methodology }\end{array}$ & Network Lifetime & Data Fusion & Nodes mobility & $\begin{array}{l}\text { Improved } \\
\text { factor }\end{array}$ & $\begin{array}{l}\text { Data Transfer } \\
\text { Rate }\end{array}$ & $\begin{array}{l}\text { Data delivery } \\
\text { model }\end{array}$ \\
\hline SEP & $\begin{array}{l}\text { Hierarchical } \\
\text { Routing }\end{array}$ & Moderate & Yes & Nodes are stationary & Stability Region & Low & Clustered head \\
\hline H-HEED & $\begin{array}{l}\text { Cluster-Based or } \\
\text { Hierarchical } \\
\text { Routing }\end{array}$ & Good & $\begin{array}{l}\text { Yes with } \\
\text { moderate delay } \\
\text { factor. }\end{array}$ & Nodes are Quasi-stationary & $\begin{array}{l}\text { Reduced Inter-Cluster } \\
\text { Communication Cost and } \\
\text { Improved Network Lifetime }\end{array}$ & $\begin{array}{c}\text { Moderately High } \\
\text { due to improved } \\
\text { packet delivery } \\
\text { ratio } \\
\end{array}$ & Hybrid \\
\hline CHR & $\begin{array}{l}\text { Hierarchical } \\
\text { Routing with } \\
\text { Relaying }\end{array}$ & $\begin{array}{l}\text { Prolonged } \\
\text { Due to H-Sensors }\end{array}$ & $\begin{array}{l}\text { Yes by } \\
\text { H-sensors }\end{array}$ & Nodes are immobile & $\begin{array}{l}\text { Improved Network performance } \\
\text { in terms of Routing }\end{array}$ & $\begin{array}{l}\text { Higher Packet } \\
\text { Delivery Ratio }\end{array}$ & $\begin{array}{l}\text { Multi-Hop using } \\
\text { Clustered Head }\end{array}$ \\
\hline DEEC & $\begin{array}{l}\text { Deterministic } \\
\text { Hierarchical } \\
\text { Routing }\end{array}$ & $\begin{array}{l}\text { Prolonged as compared } \\
\text { to SEP }\end{array}$ & Yes & Micro-Mobile/Stationary & $\begin{array}{l}\text { Minimized } \\
\text { Computational-overhead cost to } \\
\text { improve the residual energy of } \\
\text { the node. }\end{array}$ & Moderate & $\begin{array}{l}\text { Single-Hop Direct } \\
\text { link Clustered } \\
\text { Head connectivity }\end{array}$ \\
\hline UCR & $\begin{array}{l}\text { Greedy Geographic } \\
\text { Hierarchical } \\
\text { Routing }\end{array}$ & $\begin{array}{l}\text { Better than H-HEED } \\
\text { due to multi-hop } \\
\text { routing to mitigate } \\
\text { hotspot problem } \\
\end{array}$ & $\begin{array}{l}\text { Yes; because of } \\
\text { Link Symmetry }\end{array}$ & $\begin{array}{l}\text { Nodes and base station are } \\
\text { stationary }\end{array}$ & $\begin{array}{l}\text { Allay of Hotspot problem to have } \\
\text { prolonged source-driven network }\end{array}$ & $\begin{array}{l}\text { High but prone to } \\
\text { error due to noise } \\
\text { in the real } \\
\text { environment }\end{array}$ & $\begin{array}{l}\text { Multi-Hop } \\
\text { Inter-Cluster } \\
\text { Routing using } \\
\text { Relay Nodes } \\
\end{array}$ \\
\hline DEBC & $\begin{array}{l}\text { Probabilistic } \\
\text { Hierarchical } \\
\text { Routing }\end{array}$ & Good & $\begin{array}{l}\text { Yes with } \\
\text { relaying }\end{array}$ & Micro-Mobile/Stationary & $\begin{array}{c}\text { The ratio of Residual Energy to } \\
\text { the average energy of the } \\
\text { network }\end{array}$ & Moderate & $\begin{array}{l}\text { Single-Hop Direct } \\
\text { link connectivity } \\
\text { Direct link } \\
\text { connectivity }\end{array}$ \\
\hline PRODUCE & $\begin{array}{c}\text { Unequal-Sized } \\
\text { Hierarchical } \\
\text { Routing with } \\
\text { localized } \\
\text { probabilities } \\
\end{array}$ & $\begin{array}{l}\text { Prolonged in case of } \\
\text { densely distributed } \\
\text { nodes }\end{array}$ & $\begin{array}{l}\text { Yes by cluster } \\
\text { heads closer to } \\
\text { BS }\end{array}$ & $\begin{array}{l}\text { Stationary based on } \\
\text { Stochastic Geometry }\end{array}$ & $\begin{array}{l}\text { Balanced coverage time and } \\
\text { network lifetime by solving the } \\
\text { hot-spot problem }\end{array}$ & High & $\begin{array}{c}\text { Multi-hop } \\
\text { intracluster and } \\
\text { inter-cluster data } \\
\text { routing }\end{array}$ \\
\hline C4SD & $\begin{array}{l}\text { Service Discovery } \\
\text { Routing }\end{array}$ & $\begin{array}{l}\text { Prolonged by high } \\
\text { Pareto index }\end{array}$ & $\begin{array}{l}\text { Yes to avoid } \\
\text { chain reactions }\end{array}$ & Mobile & $\begin{array}{l}\text { Hit Ratio is improved to } 98 \% \text { and } \\
\text { minimized communication cost }\end{array}$ & High & $\begin{array}{c}\text { Multi-hop } \\
\text { Cluster-Based } \\
\text { Service Discovery } \\
\end{array}$ \\
\hline EEHC & $\begin{array}{l}\text { Hierarchical } \\
\text { Routing }\end{array}$ & Moderately High & $\begin{array}{l}\text { Yes followed by } \\
\text { data } \\
\text { compression by } \\
\text { the cluster head }\end{array}$ & Stationary & $\begin{array}{l}\text { Network lifetime by weighted } \\
\text { election probabilities }\end{array}$ & $\begin{array}{l}\text { Moderately high } \\
\text { due to an } \\
\text { improved stable } \\
\text { region of the } \\
\text { network }\end{array}$ & $\begin{array}{l}\text { Single-Hop Direct } \\
\text { link connectivity }\end{array}$ \\
\hline SDEEC & $\begin{array}{c}\text { Stochastic } \\
\text { Distributed Routing }\end{array}$ & $\begin{array}{l}\text { Better than DEEC and } \\
\text { SEP }\end{array}$ & Yes & Micro-Mobile/Stationary & $\begin{array}{l}\text { FND improved by a factor of } \\
\qquad 80-110 \%\end{array}$ & High & $\begin{array}{l}\text { Single-Hop Direct } \\
\text { link connectivity }\end{array}$ \\
\hline CMHT & $\begin{array}{l}\text { Cluster-Head } \\
\text { Multi-Hop } \\
\text { Hierarchical } \\
\text { Routing }\end{array}$ & Moderately High & Yes & $\begin{array}{l}\text { Stationary with a fixed } \\
\text { intermediate distance }\end{array}$ & $\begin{array}{l}\text { Method of cluster head election, } \\
\text { and extension of Stable phase of } \\
\text { data communication time }\end{array}$ & $\begin{array}{l}\text { High but } \\
\text { degrades as the } \\
\text { distance across } \\
\text { the network } \\
\text { increases }\end{array}$ & $\begin{array}{l}\text { Multi-Hop Cluster } \\
\text { Head Based } \\
\text { Service Discovery }\end{array}$ \\
\hline DDEEC & $\begin{array}{l}\text { Distributed Energy } \\
\text { Efficient Routing }\end{array}$ & $\begin{array}{l}\text { Prolonged as compared } \\
\text { to SEP and DEEC }\end{array}$ & Yes & Micro-Mobile/Stationary & $\begin{array}{l}\text { Network lifetime and first node } \\
\text { dead time is improved by a factor } \\
\text { of } 15 \% \text { than DEEC and by } 30 \% \\
\text { than SEP }\end{array}$ & Very High & $\begin{array}{l}\text { Single-Hop } \\
\text { Clustered Head } \\
\text { Direct link } \\
\text { connectivity } \\
\end{array}$ \\
\hline TDEEC & $\begin{array}{l}\text { Threshold } \\
\text { Distributed Energy } \\
\text { Efficient Routing }\end{array}$ & $\begin{array}{l}\text { Prolonged as compared } \\
\text { to SEP and DEEC }\end{array}$ & $\begin{array}{l}\text { Yes, } \\
\text { data-centric } \\
\text { fusion }\end{array}$ & $\begin{array}{l}\text { Static Uniform Random } \\
\text { Deployment }\end{array}$ & Stability Region & Very High & $\begin{array}{l}\text { Single-Hop } \\
\text { Clustered Head } \\
\text { Direct link } \\
\text { connectivity } \\
\end{array}$ \\
\hline WEP & $\begin{array}{l}\text { Distributed Energy } \\
\text { Efficient Routing }\end{array}$ & $\begin{array}{c}\text { Prolonged as compared } \\
\text { to SEP }\end{array}$ & Yes & Stationary & Stability Region & Moderately High & $\begin{array}{l}\text { Single-Hop Direct } \\
\text { link connectivity }\end{array}$ \\
\hline EAERP & $\begin{array}{l}\text { Metaheuristic } \\
\text { Energy-Aware } \\
\text { Routing }\end{array}$ & Good & $\begin{array}{l}\text { Yes at Cluster } \\
\text { Head nearest to } \\
\text { the base station }\end{array}$ & Stationary & $\begin{array}{l}\text { Stability Region and Network } \\
\text { Lifetime }\end{array}$ & Moderately High & $\begin{array}{c}\text { Single-Hop } \\
\text { Clustered Head } \\
\text { Direct link } \\
\text { connectivity } \\
\end{array}$ \\
\hline EACP & $\begin{array}{l}\text { Energy-Aware } \\
\text { Hierarchical } \\
\text { Routing } \\
\end{array}$ & Good & $\begin{array}{l}\text { Yes at the } \\
\text { advanced nodes }\end{array}$ & Micro-Mobile/Stationary & $\begin{array}{l}\text { Stability Region, Network } \\
\text { Lifetime and Throughput }\end{array}$ & High & $\begin{array}{l}\text { Multi-Hop Cluster } \\
\text { Head Based } \\
\text { Service Discovery }\end{array}$ \\
\hline BEENISH & $\begin{array}{l}\text { Balanced Energy } \\
\text { Efficient } \\
\text { Hierarchical } \\
\text { Routing } \\
\end{array}$ & $\begin{array}{l}\text { Prolonged as compared } \\
\text { to DEEC, DDEEC }\end{array}$ & $\begin{array}{l}\text { Yes at the } \\
\text { advanced nodes }\end{array}$ & Micro-Mobile/Stationary & $\begin{array}{l}\text { First Node Dead Time is } \\
\text { improved }\end{array}$ & Very High & $\begin{array}{l}\text { Single-Hop } \\
\text { Clustered Head } \\
\text { Direct link } \\
\text { connectivity } \\
\end{array}$ \\
\hline IDHR & $\begin{array}{l}\text { Cluster-based } \\
\text { Probabilistic } \\
\text { Hierarchical } \\
\text { Routing }\end{array}$ & $\begin{array}{l}\text { Prolonged with } \\
\text { increased (stability } \\
\text { region, Half node } \\
\text { Deadtime(HND)) }\end{array}$ & $\begin{array}{l}\text { Yes, at Cluster } \\
\text { Head }\end{array}$ & Stationary & $\begin{array}{l}\text { Stability Region, Network } \\
\text { Lifetime and HND }\end{array}$ & High & $\begin{array}{l}\text { Dual- Hop } \\
\text { Cluster-based } \\
\text { Routing }\end{array}$ \\
\hline MEEC & $\begin{array}{l}\text { Cluster-based } \\
\text { Probabilistic } \\
\text { Hierarchical } \\
\text { Routing }\end{array}$ & $\begin{array}{l}\text { Relatively Higher than } \\
\text { IDHR(due to } 4 \text { Sink } \\
\text { Nodes) }\end{array}$ & $\begin{array}{l}\text { Yes, at Cluster } \\
\text { Head }\end{array}$ & Stationary & $\begin{array}{l}\text { Stability Region, Network } \\
\text { Lifetime and HND }\end{array}$ & $\begin{array}{l}\text { Very High(Due to } \\
\text { the absence of } \\
\text { Hot-Spot } \\
\text { Problem) }\end{array}$ & $\begin{array}{l}\text { Single-Hop Direct } \\
\text { link connectivity }\end{array}$ \\
\hline
\end{tabular}


Table3: Comparison on the basis of Simulated Parameters

\begin{tabular}{|c|c|c|c|c|c|c|c|}
\hline Protocol & $\begin{array}{l}\text { Deployment Area/ Threshold } \\
\text { Distance }\left(d_{c r o s s}\right)\end{array}$ & No. of Data Sink & $\begin{array}{c}\text { Initial Energy of } \\
\text { Nodes } E_{0} \text { (in } \\
\text { Joules) }\end{array}$ & $\begin{array}{c}\text { Transmitting and } \\
\text { receiving energy } \\
E_{\text {eles }}\end{array}$ & $\begin{array}{l}\text { Data } \\
\text { Packet } \\
\text { Size } \\
\end{array}$ & $\begin{array}{c}\text { Amplification Energy } \\
E_{f x} \text { for smaller distance }\end{array}$ & $\begin{array}{c}\text { Amplification Energy } \\
E_{\text {amp }} \text { for larger distance }\end{array}$ \\
\hline SEP & $100 * 100 \mathrm{~m} / 70 \mathrm{~m}\left(\sqrt{E_{f s} / E_{a m p}}\right)$ & 1 & $0.5 \mathrm{~J}$ & $50 \mathrm{~nJ} / \mathrm{bit}$ & 4000bits & $\frac{10 p J}{\text { bit }} / m^{2}$ & $\frac{0.0013 p J}{b i t} / m^{4}$ \\
\hline H-HEED & $\begin{array}{l}100 * 100 \mathrm{~m} / \\
70 \mathrm{~m}\end{array}$ & $\begin{array}{l}1 \text { (at the center } \\
(50,50))\end{array}$ & $0.5 \mathrm{~J}$ & $50 \mathrm{n} / /$ bit & 4000bits & $\frac{10 p J}{b i t} / m^{2}$ & $\frac{0.0013 p J}{b i t} / m^{4}$ \\
\hline CHR & $300 * 300 \mathrm{~m} / 70 \mathrm{~m}$ & 1 or more & $0.5 \mathrm{~J}$ & $50 \mathrm{~nJ} / \mathrm{bit}$ & 4000bits & $\frac{10 p J}{b i t} / m^{2}$ & $\frac{0.0013 p J}{b i t} / m^{4}$ \\
\hline DEEC & $\begin{array}{l}100 * 100 \mathrm{~m} / \\
70 \mathrm{~m}(\end{array}$ & $\begin{array}{l}\text { 1(located at focal } \\
\text { point or at the center) }\end{array}$ & $0.5 \mathrm{~J}-2.25 \mathrm{~J}$ & $50 \mathrm{~nJ} / \mathrm{bit}$ & 4000bits & $\frac{10 p J}{b i t} / m^{2}$ & $\frac{0.0013 p J}{b i t} / m^{4}$ \\
\hline UCR & $(0,0)-(400,200) \mathrm{m} / 87 \mathrm{~m}$ & 1 at $(500,100) \mathrm{m}$ & $1 \mathrm{~J}$ & $50 \mathrm{~nJ} / \mathrm{bit}$ & 4000bits & $\frac{10 \mathrm{pJ}}{\text { bit }} / \mathrm{m}^{2}$ & $\frac{0.0013 p J}{b i t} / m^{4}$ \\
\hline DEBC & $500 * 500 \mathrm{~m} /-$ & 1 at $(250,250) m$ & $20 \mathrm{~J}$ & - & - & $\frac{10 p J}{b i t} / m^{2}$ & $\frac{0.0013 p J}{b i t} / m^{4}$ \\
\hline PRODUCE & $\begin{array}{l}\text { Radius-100m(circular area)/ } \\
87 \mathrm{~m}\end{array}$ & 1 at $(0,0)$ & $2 \mathrm{~J}$ & $50 \mathrm{~nJ} /$ bit & 500 bytes & $\frac{10 p J}{b i t} / m^{2}$ & $\frac{0.0013 p J}{b i t} / m^{4}$ \\
\hline C4SD & $500 * 500 \mathrm{~m} /-$ & 1 & - & $50 \mathrm{~nJ} / \mathrm{bit}$ & - & $\frac{10 p J}{b i t} / m^{2}$ & $\frac{0.0013 p J}{b i t} / m^{4}$ \\
\hline EEHC & $100 * 100 \mathrm{~m} / 70 \mathrm{~m}$ & $\begin{array}{l}1 \text { (at the center } \\
(50,50))\end{array}$ & $0.5 \mathrm{~J}$ & $50 \mathrm{~nJ} / \mathrm{bit}$ & 4000bits & $\frac{10 p J}{b i t} / m^{2}$ & $\frac{0.0013 p J}{b i t} / m^{4}$ \\
\hline SDEEC & $100 * 100 \mathrm{~m} / 70 \mathrm{~m}$ & $\begin{array}{l}\text { (at the center } \\
(50,50))\end{array}$ & $0.5 \mathrm{~J}$ & $5 n j /$ bit & 4000bits & $\frac{10 p J}{b i t} / m^{2}$ & $\frac{0.0013 p J}{b i t} / m^{4}$ \\
\hline СМHТ & $100 * 100 \mathrm{~m} / 70 \mathrm{~m}$ & 1(at the $(50,, 175))$ & $1.5 \mathrm{~J}$ & $50 \mathrm{~nJ} / \mathrm{bit}$ & - & $\frac{10 p J}{\text { bit }} / m^{2}$ & $\frac{0.0013 p J}{b i t} / m^{4}$ \\
\hline DDEEC & $100 * 100 \mathrm{~m} / 70 \mathrm{~m}$ & $\begin{array}{l}\text { 1(at the center } \\
(50,50))\end{array}$ & $0.5 \mathrm{~J}$ & $5 n / /$ bit & 4000bits & $\frac{10 p J}{b i t} / m^{2}$ & $\frac{0.0013 \mathrm{pJ}}{\text { bit }} / \mathrm{m}^{4}$ \\
\hline TDEEC & $100 * 100 \mathrm{~m} / 70 \mathrm{~m}$ & $\begin{array}{l}\text { 1(at the center } \\
(50,50))\end{array}$ & $0.5 \mathrm{~J}$ & $5 n j /$ bit & 4000bits & $\frac{10 p J}{b i t} / m^{2}$ & $\frac{0.0013 p J}{b i t} / m^{4}$ \\
\hline WEP & $100 * 100 \mathrm{~m} / 70 \mathrm{~m}$ & $\begin{array}{c}1 \text { (at the center } \\
(50,50))\end{array}$ & $0.1 \mathrm{~J}$ & $50 \mathrm{n} / /$ bit & 4000bits & $\frac{10 p J}{b i t} / m^{2}$ & $\frac{0.0013 \mathrm{pJ}}{\text { bit }} / \mathrm{m}^{4}$ \\
\hline EAERP & $100 * 100 \mathrm{~m} / 70 \mathrm{~m}$ & $\begin{array}{c}\text { 1(either at center or } \\
\text { at the extreme } \\
\text { corner) }\end{array}$ & $0.5 \mathrm{~J}$ & $50 \mathrm{~nJ} / \mathrm{bit}$ & 4000bits & $\frac{10 p J}{b i t} / m^{2}$ & $\frac{0.0013 \mathrm{pJ}}{\text { bit }} / \mathrm{m}^{4}$ \\
\hline EACP & $100 * 100 \mathrm{~m} / 70 \mathrm{~m}$ & $\begin{array}{c}\text { (at the center } \\
(50,50))\end{array}$ & $0.5 \mathrm{~J}$ & $5 \mathrm{nj} /$ bit & 4000bits & $\frac{10 p J}{b i t} / m^{2}$ & $\frac{0.0013 p J}{b i t} / m^{4}$ \\
\hline BEENISH & $\begin{array}{l}100 * 100 \mathrm{~m} / \\
70 \mathrm{~m}(\end{array}$ & $\begin{array}{l}\text { 1(located at focal } \\
\text { point or at the center) }\end{array}$ & $0.5 \mathrm{~J}-2.25 \mathrm{~J}$ & $50 \mathrm{~nJ} / \mathrm{bit}$ & 4000bits & $\frac{10 \mathrm{pJ}}{\text { bit }} / \mathrm{m}^{2}$ & $\frac{0.0013 p J}{b i t} / m^{4}$ \\
\hline IDHR & $100 * 100 \mathrm{~m} / 87 \mathrm{~m}$ & 1(at the middle) & $1 \mathrm{~J}$ & $50 \mathrm{ny} /$ bit & 2000bits & $\frac{10 p J}{b i t} / m^{2}$ & $\frac{0.0013 p J}{\text { bit }} / \mathrm{m}^{4}$ \\
\hline MEEC & $100 * 100 \mathrm{~m} / 87 \mathrm{~m}$ & 4(on each periphery) & $1 \mathrm{~J}$ & $50 \mathrm{n} / /$ bit & 2000bits & $\frac{10 p J}{b i t} / m^{2}$ & $\frac{0.0013 p J}{b i t} / m^{4}$ \\
\hline
\end{tabular}

\section{CONCLUSION}

To revamp the network stability region and lifetime, the extensive concern is to have adoption of optimum Cluster head election strategies as their majority of energy factor is spent in Data Aggregation, Data Forwarding, Compressive Sensing and Data Communication across the network. This paper compares various heterogeneous(Het-Net) routing and clustering methodologies footing on the grounds of decisive attributes like cluster head mobility, level of heterogeneity, cluster density, data transfer rate, transmitting and receiving energy required, amplification energy values, etc. which in turn are decisive factors to improve network lifetime, throughput, response time, hit ratio and above all energy efficiency of the system.

\section{REFERENCES}

1. I.F. Akyildiz, W. Su, Y. Sankarasubramaniam, E. Cayirci, 001 Wireless sensor networks: a survey, Comput. Networks. 38 (2002) 393-422.

2. S. Arjunan, P. Sujatha, A survey on unequal clustering protocols in Wireless Sensor Networks, J. King Saud Univ. - Comput. Inf. Sci. 31 (2019) 304-317. 


\section{Parametric Assay of Energy Adept Clustering Protocols for Het-Net Wireless Sensor Networks}

3. C. Duan, H. Fan, A distributed energy balance clustering protocol for heterogeneous wireless sensor networks, 2007 Int. Conf. Wirel. Commun. Netw. Mob. Comput. WiCOM 2007. (2007) 2469-2473.

4. B. Elbhiri, S. Rachid, S. El Fkihi, D. Aboutajdine, Developed Distributed Energy-Efficient Clustering (DDEEC) for heterogeneous wireless sensor networks, 2010 5th Int. Symp. I/V Commun. Mob. Networks, ISIVC 2010. (2010).

5. B. Elbhiri, R. Saadane, D. Aboutajdine, Stochastic distributed energy-efficient clustering (SDEEC) for heterogeneous wireless sensor networks, ICGST-CNIR J. 9 (2009) 11-17.

6. F. Engmann, F.A. Katsriku, J. Abdulai, K.S. Adu-manu, F.K. Banaseka, Prolonging the Lifetime of Wireless Sensor Networks: A Review of Current Techniques, 2018 (2018).

7. C. Gherbi, Z. Aliouat, M. Benmohammed, A survey on clustering routing protocols in wireless sensor networks, 2017.

8. M. Golam Rashed, M. Hasnat Kabir, S. Enayet Ullah, WEP: An Energy-Efficient Protocol for Cluster-Based Heterogeneous Wireless Sensor Network, Int. J. Distrib. Parallel Syst. 2 (2011) 54-60.

9. R. Kacimi, R. Dhaou, A. Beylot, Ad Hoc Networks Load balancing techniques for lifetime maximizing in wireless, AD HOC NETWORKS. (2013).

10. C. Kaibing, Unequal cluster-based routing protocol in wireless sensor networks, J. Networks. 8 (2013) 2656-2662.

11. E.A. Khalil, B.A. Attea, Energy-aware evolutionary routing protocol for dynamic clustering of wireless sensor networks, Swarm Evol. Comput. 1 (2011) 195-203.

12. J.H. Kim, C.S. Hussain, W.C. Yang, D.S. Kim, M.S. Park, Produce A probability-driven unequal clustering mechanism for wireless sensor networks, Proc. - Int. Conf. Adv. Inf. Netw. Appl. AINA. (2008) 928-933.

13. H. Kour, A.K. Sharma, Hybrid Energy Efficient Distributed Protocol for Heterogeneous Wireless Sensor Network, Int. J. Comput. Appl. 4 (2010) $1-5$.

14. M. Kowshalya, Sukanya, Clustering Algorithms for Heterogeneous Wireless Sensor Networks - A Brief Survey, Int. J. Ad Hoc, Sens. Ubiquitous Comput. 2 (2011) 57-69.

15. D. Kumar, T.C. Aseri, R.B. Patel, EEHC: Energy efficient heterogeneous clustered scheme for wireless sensor networks, Comput. Commun. 32 (2009) 662-667.

16. S. Kumar, S. Kumar, B. Bhushan, Energy-Aware Clustering Protocol (EACP) For Heterogeneous WSN, Int. J. Comput. Networks Commun. 6 (2014) 23-37.

17. C.S. on routing protocols for large-scale wireless sensor networks Li, H. Zhang, B. Hao, J. Li, A Survey on routing protocols for large-scale wireless sensor networks, Sensors. 11 (2011) 3498-3526.

18. R.S. Marin-Perianu, J. Scholten, P.J.M. Havinga, P.H. Hartel, Cluster-based service discovery for heterogeneous wireless sensor networks, Int. J. Parallel, Emergent Distrib. Syst. 23 (2008) 325-346.

19. S. Parul, S. Ajay K, Energy Efficient Scheme for Clustering Protocol Prolonging the Lifetime of Heterogeneous Wireless Sensor Networks, Int. J. Comput. Appl. 6 (2010) 975-8887.

20. X. Qiao, F. Ma, Y. Chen, W. Yao, The protocol of cluster multi-hop transmission based on heterogeneous wireless sensor networks, Proc. 2009 Int. Conf. Comput. Intell. Softw. Eng. CiSE 2009. (2009) 2006-2009.

21. L. Qing, Q. Zhu, M. Wang, Design of a distributed energy-efficient clustering algorithm for heterogeneous wireless sensor networks, 29 (2006) 2230-2237.

22. T.N. Qureshi, N. Javaid, A.H. Khan, A. Iqbal, E. Akhtar, M. Ishfaq, BEENISH: Balanced energy-efficient network-integrated super heterogeneous protocol for wireless sensor networks, Procedia Comput. Sci. 19 (2013) 920-925.

23. A.B. Smaragdakis, Georgios, Ibrahim Matta, SEP : A Stable Election Protocol for clustered, Proc. 2nd Int. Work. SANPA. (2004) 1-11.

24. S. Verma, N. Sood, A.K. Sharma, A novelistic approach for energy-efficient routing using single and multiple data sinks in heterogeneous wireless sensor network, (2019).

25. Xiaojiang Du, Fengjing Lin, Improving Routing in Sensor Networks with Heterogeneous Sensor Nodes, (2005) 2528-2532.

\section{AUTHORS PROFILE}

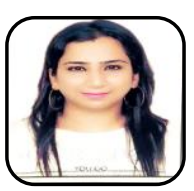

Ridhi Kapoor received her B.Tech. Degree from Punjab Technical University, in 2011; M.Tech. Degree, from Guru Nanak Dev University in 2013 and is pursuing a Ph.D. from Guru Nanak Dev University. She has qualified GATE in 2016. She has more than 6 years of experience in teaching graduate and postgraduate students. She is an Associate Member of the Institution of Engineers. She has 10 research publications to her credit. She specializes in: Wireless Sensor Networks, IoT, and Distributed Databases.

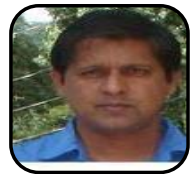

Dr. Sandeep Sharma is Professor and Head Department of at Department of Computer Engineering \& Technology at GNDU Amritsar. He did his B.E.(CSE)., M.E.(CSE), Ph.D. from GNDU, Amritsar. He has more than 20 years of teaching experience. He has 62 Journal publications and 14 Conference publications to his credit. He has 15 memberships of the international and national repute. He specializes in the area of Cloud Computing, Parallel Processing, and Data Security. 